\title{
Software Process Improvement in Small and Medium Software Organisations of India
}

\author{
M.P.Thapliyal \\ Associate Professor \\ Department of Computer Science \\ HNB Garhwal University(Central \\ University), Srinagar(Garhwal) \\ Uttarakhand, India
}

\author{
Pratibha Dwivedi \\ DAV Public School, \\ Vasantkunj, New Delhi, \\ India
}

\begin{abstract}
The challenge for software development enterprises is to find a path to apply Software Process Improvement (SPI) technologies to realize their company's improvement goals. The most pressing requirements for improvement paradigms are that these SPI technologies are not only effective but also realize tangible results quickly, which can be implemented incrementally. This paper focuses on the key issues in Software Process Improvement paradigm, in comparison to the current process in India to those of the standard models used internationally. This research also suggests a software process practices model for Indian small and medium software companies that require collaboration and strengthening to transform their current perspective into inseparable global IT scenario. This paper also gives a quantitative study and is based on questionnaires and interviews of Indian small and medium software organizations.
\end{abstract}

Key words

Software Process Improvement, software organizations, IT

\section{INTRODUCTION}

To build up a software product or system, it is necessary to step forward through some predictable steps, which helps to create timely, high quality results. More formally, a software process is a framework for the tasks that are required to build high quality software [1]. Therefore, software process defines the approach that is taken as software is engineered. Another reason why it is important is that a process provides organizational stability and more control to its activity. However, there are some common misconceptions in the industry about process. It is assumed that a process interferes with creativity, creates bureaucracy, useful only for large projects and implementing a process costs high. Although everyone in the software industry understands the importance of having motivated, quality workforce and the latest technology, we do not want to realize that even the finest people cannot perform at their best when the process is not understood or the process is not operating at its best. With offshore outsourcing and growing countries like India is in a position of exporting their local Information Technology services. However, what is the state of Information Technology in India? Few cases of Indian software companies have the maturity of CMM level 5 like NIIT,Software Solutions, Patni Computer Systems Limited, Satyam Computer Services Limited, Tata Consultancy Services, Larsen \& Turbo Infotech Limited and Infosys Technologies Limited.

\section{CURRENT SCENARIO OF INDIA IN SPI}

The Software Industry in India plays a prominent role in the Indian Economy. As per a report given by NASSCOM CEO Summit in the year 2008, 85\% members of NASSCOM are Small-to-Medium-Sized Enterprises (SMEs). They generated revenue of about US $\$ 12-15 \mathrm{~B}$ in software exports in the year 2008. Around $96 \%$ of Indian software SMEs supported to run 23 million businesses in US, which generate $64 \%$ of new employment. Typical Indian software SME will have revenue less than Rs.100 million[2]. During the late nineties, the SPIRE (Software Process Improvement in Regions of Europe) programme applied the SPICE model to a variety of SMEs[3].However, the research indicates that only a small percentage of Indian indigenous software development companies have implemented formal SPI assessment methods. One such study emphasizes that the Indian software companies are reluctant to engage in formal SPI assessments because of the high cost and resources involved. The findings of literature survey showed that Indian software SMEs are employing fewer than 20 people. Many Indian SMEs compete with big organizations for project from prospective clients[4]. One of the major problems faced by the Indian software SMEs is the lack of process assessment or process improvement activities that are carried out in big organizations, which not only help to improve the project standard but also to minimize the time, labor and fiscal budget of the project. Small companies give little importance to these activities; one employee plays multiple roles in the company, for example a programmer might play the role of a technical architect, developer and tester simultaneously. This scenario is quite common in an SME environment. This not only affects the quality of work but also the impact and significance of the project. Many of the smaller companies oppose the standards due to the expensive compliance effort, both in time and money. Some of the shortcomings faced by SMEs are: Excessive documentation. Extensive number of Specific Practices (SP). Requirement of extensive resources. High training costs. Practices independent of project type. . Lack of guidance in satisfying project and development team needs. Many of the smaller companies oppose the CMMI model due to the expensive compliance effort, both in time and money[2,5]

\section{INDIAN SOFTWARE INDUSTRY}

The software industry is a relatively young industry in India, with most of the organizations being less than 20 years old. The boom and growth in the industry really came in the late 90 s, after the economic liberalization within the country. (With liberalization, 
import export restrictions were eased which made it much easier to import computing equipment and export software services without government permission, import duties were slashed resulting in reduced cost, and government regulations for starting companies eased.) Starting with a total turnover of less than $\$ 100$ million before 1990 , the total turnover is now over $\$ 5$ Billion! The industry has been growing at over $50 \%$ every year since around 1995. Information technology and IT-enabled services are projected to become a $\$ 50$ - $\$ 80$ Billion industry before the end of this decade. Overall, the industry has done remarkably well, continues to do so, and is expected to do so for the foreseeable future. The Indian software industry has been maturing in many dimensions. In the value chain, it started primarily as a subcontractor for technical manpower. Later it gradually shifted to doing complete parts or phases of projects, usually the later phases of coding and testing. From this, it matured to providing complete solutions off-shore (i.e. in India). Today most leading companies are operating in the high-end software services business and are also making efforts to enter the products segment. The industry has also matured in the process and quality dimension. In the early days of technical manpower based solutions, the focus was squarely on software work-products. As the nature of work changed, the process orientation also took its root. When ISO9000 was introduced in early 90 s for software $[6,7,8]$, Indian software industry quickly adopted it in an effort to improve its quality processes and gain recognition. Hundreds of software companies got ISO certified. In the last five years or so, for process improvement, almost the entire industry moved over the software CMM [9]. And in keeping with their tradition of fast pace, within a few years, a large number of software companies matured to level 4 or level 5. India now has more than half of the total high-maturity organizations that are in the SEI's database. What is different or special about the Indian software industry? The predominance of exports marks it out as an export-led industry, but even when compared with other successful exporters such as Israel and Ireland, Indian software growth is different. Unlike Israel's industry, the Indian software industry was built mostly around customized software services rather than products. The customized software services market is a large-volume market. Many types of services, such as those involved in the maintenance of data/legacy systems, are low-value services. The Indian software industry has for the most part specialized in these relatively low-value activities and this low-value content of the software services industry is reflected in the level of productivity. Unlike the Irish software industry, domestic rather than foreign firms led Indian software growth. India's software exports are largely the products of Indian firms. The software case study also highlights two external factors that influenced the direction of growth taken by Indian software firms. First, the The data for this survey was collected from 50 small and medium software companies of Indian metro cities Bangalore and Hyderabad by sending emails with questionnaires directly to the company's managing directors, project managers and senior software development professionals. Researcher also arranged interview sessions over telephone with surveyed company's personnel to know the actual process capability of the company. A set of open-ended questions were initially prepared and later a set of specific questions on software process were prepared as data gathering techniques. Researcher combination of low wage costs vis-à-vis the rest of the world with rising wage costs relative to rest of Indian industry (as the competition for Indian software programmers became global) induced Indian firms to move away from wage arbitrage to a new kind of competition based on the organizational ability to manage the writing of software codes.

\section{RESEARCH DESIGN METHODOLOGY}

The data for this survey was collected from 50 small and medium software companies of Indian metro cities Bangalore and Hyderabad by sending emails with questionnaires directly to the company's managing directors, project managers and senior software development professionals. Researcher also arranged interview sessions over telephone with surveyed company's personnel to know the actual process capability of the company. A set of open-ended questions were initially prepared and later a set of specific questions on software process were prepared as data gathering techniques. Researcher asked the same set of questions during the phone interview as well as email sessions. Question sets were related to software process familiarity, organizational structure and financial matters in adherence to a software process and their intension for future process improvement etc.

\section{RESULTS AND DISCUSSION}

Our study conducted a survey of small and medium software companies of Bangalore and Hyderabad metro cities of India to know about their software process implementation and process improvement program using a set of questionnaires as a data gathering technique over a period of four months.. Due to our strict inclusion criteria, the number of relevant studies found was very small but the overall search process was very comprehensive and it was performed by following the recommended guidelines according in [12], to the best of our knowledge. Similarly data extraction and synthesis phase is also performed as prescribed by the practitioners with proper validation and quality assurance. Main objective of the SR was to investigate specific SPI models or techniques for small and medium software Indian companies. The systematic review did not identify any specific SPI model for small and medium software Indian companies; therefore there is a clear research gap on the proposal of a specific SPI model for small and medium software companies keeping in view the constraints and challenges. This can be achieved by extending some existing model [11] or by proposing one from scratch. The SR also revealed the characteristics of some small and medium software companies and suggested that they have tight budget constraints, have tight deadlines and they have a short term strategy. Investigated measures of success for small and medium software companies include development team and client satisfaction, increase in productivity, compliance with standards and overall operational excellence. In our survey out of 50 companies, 21 companies respond to lack of management commitment. Management commitment to software process improvement also affects the morale and dedication of people who are working to advance the cause of better processes in the organization. When management objectives change with the wind and the staff devoted to facilitating process improvement is downsized, those affected may be embittered at having months or years of their technical careers sidetracked for nothing. Once burned in such a 
fashion, they may be reluctant to step forward the next time the organization is looking for people to enable change. However our findings indicate that rest of $60 \%$ of companies had a good understanding of the human factors associated with SPI. Most companies involved developers in SPI and understood the value of communicating to developers about SPI. Furthermore companies also seemed to understand the importance of management commitment to SPI and most seemed to be successfully demonstrating such commitment. Overall our findings show that developers were responding relatively positively to SPI and that developers were most positive about SPI when they received plenty of feedback on SPI. 15 companies showed their eagerness for achieving a CMM level as their primary goal of process improvement rather than as one mechanism to help achieve the organization's real business goals. Software process improvement energy may be focused on a race to the level $\mathrm{N}$ rating, when some energy should perhaps be devoted to other problem areas that can contribute quickly to the quality, productivity, people, and management issues facing the organization. Sometimes, a company is in such a rush to reach the next maturity level that the recently implemented process improvements have not yet become well established and habitual. In such cases, the organization might actually regress back to the previous maturity level, rather than continue to climb the maturity ladder as it is attempting to do. Such regression is a surefire way to demoralize practitioners who are eager to move steadily toward a superior software engineering culture. It has been suggested from present study that such small software companies aiming at the next CMM level, make sure your software process improvement effort is aligned with corporate business and technical objectives. Mesh the process improvement activities with any other improvement initiatives that are underway, such as ISO 9001 registration, or with an established software development framework already in use. Recognize that advancing to the next CMM maturity level can take one to three years. It is not feasible to leap from an initial ad hoc development process to a super-sophisticated engineering environment in one fell swoop. Such companies goal is not to be able to proudly say that they are CMM Level 5. Goal is to develop improved software processes and more capable development engineers so that your company can prosper by offering higher quality products to your customers more efficiently than before. In a question regarding CMM's process maturity, 14 companies representatives replied, that their company have years of experience in software development and they have developed their own process that matches with their culture. They do not bother about the costly CMM/CMMI process maturity and capability certification as they have long list of corporate clients, which includes many Government institutions, Asian Development Bank (ADB), local United Nations (UN) offices, multinational companies like British American Tobacco (BAT). In 1994 they have developed the seat reservation \& ticketing system of Indian Tourism and operated this on behalf of the client until April 2002.These small software companies are only focusing on serving local software markets are not facing any problems regarding CMM/CMMI or other certification issues, however, that outside market focus will not be a factor for them because they have long time experience in this field. Gaining some levels in CMM/CMMI does not always mean that a software company would always produce high quality software within time and budget. In this survey, most of small software companies agreed that the cost of manpower is not very high in India, and a typical software company might be spending about $1 / 3$ rd of its expenditure on manpower. This makes dedicating a team for SPI for long term benefits cheaper. A survey of high maturity organizations in India indicated that most companies had dedicated manpower for SPI equal to about $1-2 \%$ of their engineering manpower [13].

\section{REFERENCES}

[1] Pressman, R. S., 2005, Software Engineering: A Practitioner's Approach, $6^{\text {th }}$ international edn, McGraw-Hill Education, Singapore.

[2] Raj Jain, PPT, "Nasscom CEO Summit 2008”, Dec 2008, www.nasscom.com

[3] Ita Richardson and Christiane Gresse von Wangenhelm "Why are small software organizations different?", IEEE Software, January/ February 2007.

[4] Minoo Shinde and Sajjan G. Shiva "CMMI Framework in Small Business Environment - A Case Study"

[5] Kathleen Coleman Dangle, Patricia Larsen, Michele Shaw, and Marvin V. Zelkowitz, "Software Process Improvement in Small Organizations: A Case Study", IEEE Software, November / December 2005.

[6] Quality Systems - Model for Quality Assurance in Design/Development, Production, Installation, and Services, Intl. Standards Organization ISO9001, Geneva, 1987.

[7] ISO9000-3: Guidelines for the application of ISO9001 to the development, supply and maintenance of software, International Standard, 1991.

[8] TickIT: A Guide to Software Quality Management System Construction and Certification Using EN29001, UK Dept. of Trade and Industry and British Computer Society, 1992.

[9] M. C. Paulk, "Indian Software Excellence: Education and Process Pay Off," Cutter IT Journal, Vol. 13, No. 2, February 2000, pp. 23-27.

[10] P. Jalote, CMM in Practice: Processes for Executing Software Projects at Infosys, Addison Wesley, 1999 (SEI Series on Software Engineering)

[11] Jianguo Li, Jinghui Li, and Hongbo Li Research on Software Process Improvement Model Based on CMM World Academy of Science, Engineering and Technology 392008 , pp 368-371

[12] J .B. Kitchenham, Guidelines for Performing Systematic Literature Review in Software Engineering, EBSE Technical Report, Keele University, Version 2.3, 2007.

[13] P. Jalote, "Use of Metrics in High Maturity Organizations", Proc. Of the SEPG-2K, Seattle, March 2000. 